\title{
Gonadotropin dependent precocious puberty in a boy with Prader Willi Syndrome
}

\author{
Gamage D. S ${ }^{1}$, Lakmini B. C ${ }^{1}$ Gunasekara B. P1 , De Silva D ${ }^{1}$, Atapattu N ${ }^{2}$ \\ ${ }^{1}$ Senior Registrar in Pediatric Endocrinology Lady Ridgeway Hospital Colombo \\ ${ }^{2}$ Consultant Pediatric Endocrinologist Lady Ridgeway Hospital Colombo
}

\begin{abstract}
Prader Willi Syndrome is a severe obesity syndrome due to the absence of paternal expression of imprinted genes localized at 15q11.2-q13. It is characterized by short stature, hypotonia, and feeding difficulties in infancy. Hypothalamic pituitary dysfunction is seen in this syndrome resulting in growth hormone defi iency and hypogonadism. Thus, the usual manifestation of this syndrome will be delayed puberty and infertility. Gonadotropin-dependent precocious puberty is a very rare manifestation, where some cases are associated with growth hormone therapy. We report eight years and eight-month-old boy presented to us with Prader Willi Syndrome and type 2 diabetes, who developed central precocious puberty.
\end{abstract}

Key Words: Prader-Willi syndrome, Gonadotropin dependent precocious puberty, Type 2 Diabetes, Gonadotropin analogues

Correspondence email: dilharasenanigamage@gmail.com

https://orcid.org/0000-0001-5413-116X

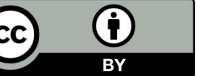

This is an open-access article distributed under the terms of the Creative Commons Attribution License, which permits unrestricted use, distribution, and reproduction in any medium, provided the original author and source are credited (CC BY 4.0)

Introduction

Prader-Willi syndrome is a genetic disorder caused by the absence of paternal expression of several imprinted genes located on chromosome $15 \mathrm{com}$ monly due to deletion or uniparental disomy (1).

Characteristic features of Prader Willi Syndrome include short stature with severe obesity, hypoplastic external genitalia,

cryptorchidism, delayed puberty, suggesting a dysfunction of the hypothalamic-pituitary-

gonadal axis $(1,2,5)$. Some children with Prader Willi Syndrome have experienced premature adrenarche which is not linked to obesity (3). Gonadotropin-dependent precocious puberty is extremely rare among boys with this syndrome.

\section{Case Report}

Eight years and eight months old child diagnosed with Prader Willi syndrome (PWS) based on clinical features, was referred to us from a tertiary care hospital for the management of type 2 Diabetes Mellitus. He was the second-born child to a non-consanguineous parent. He was born preterm at the POA of 29 weeks with a birth weight of $1.03 \mathrm{~kg}$. He was managed in the premature baby unit for nearly one and half month's duration for severe respiratory distress and needed ventilation. Initially, he was noted to have difficulty in feeding and needed support. However, after four and half months of age, he was found to have excessive weight gain crossing the centiles. He had hypotonia, global developmental delay snoring at night with no daytime somnolence at presentation. He was attending a special school and was followed up in a special clinic for the global 
developmental delay and learning difficultie. The diagnosis of the syndrome was made based on the consensus diagnostic criteria for Prader Willi syndrome (4). He scored 8 and fulfilled 5 major criteria and 6 minor criteria.

Osmotic symptoms such as polyuria and polydipsia led to the diagnosis of type 2 Diabetes mellitus.

On examination he was a short obese child with weight was $35.2 \mathrm{~kg}$ plotting on the 95th centile and height was $124 \mathrm{~cm}$ at the 25 th to 50 th centile. His growth velocity which was $3 \mathrm{~cm}$ per year was advanced to $7 \mathrm{~cm}$ per year since the age of 6 years and 9 months. He had almond-shaped eyes, a prominent forehead, short chubby hands, and feet characteristic of PWS. His genital examination revealed stage two pubic hair with a penile length of $5 \mathrm{~cm}$. His right testicle was $4 \mathrm{ml}$ and his left was $5 \mathrm{ml}$. Blood pressure both systole and diastole fell in between the 90th and 95th centile.

His $\mathrm{LH}$ was $0.7 \mathrm{IU} / 1$ and FSH was $7.21 \mathrm{IU} / 1$. His bone age was 11 years at the chronological age of 8 years according to the Tanner - Whitehouse method. His predicted adult height according to the standard Bone Xpert software was well below the mid parental height. The MRI of the hypothalamus-pituitary region was normal.

The clinical features (bilateral testicular volumes of 4-5 ml with a growth spurt) radiological advanced bone age and biochemical features LH greater than $0.2 \mathrm{IU} / \mathrm{L}$ were consistent with a diagnosis of gonadotropin-dependent precocious puberty in this 8 year and eight-month-old boy with PWS.

He was not treated with gonadotrophin analogs as he was close to 9 years of age and did not have any behavioral issues such as sexual behaviors, aggression, or social mal- behaviors. Routine management for Prader Willi Syndrome and Diabetes was carried out.

\section{Discussion}

Prader Willi Syndrome is characterized by hypotonia since birth, difficulties in feeding in infancy followed by rapid weight gaining associated with severe obesity, and short stature towards the childhood to adult life. It is associated with variable degrees of learning disability, developmental delay, hypogonadism, and hypothalamic-pituitary insufficiency $(1,2,5)$, with delayed puberty and hypogonadism $(1,2,3,5$,$) . However rare cases of central precocious$ puberty have been reported in the world $(1,2,3,5)$.

The prevalence of this syndrome is 1 in 15000 to 1 in 30000 (1). It is due to the absence of paternal expression of imprinted genes on chromosome 15q11.2-q13 (1). The diagnosis must be made depending on the clinical criteria and confi med with genetic testing.

The mechanism of gonadotrophin-dependent precocious puberty in PWS is not well established. MKRN3 and DLK1 genes found on chromosome 15 are considered important in the causation of gonadotrophin-dependent precocious puberty (3). Loss-of-function mutations of the above-imprinted genes result in central precocious puberty in a normal individual (3). It is postulated that larger deletions of the chromosome 15q11-13, including MKRN3, could result in gonadotropin-dependent precocious puberty in Prader-Willi syndrome (3).

However, few reported cases have shown that gonadotropin-dependent precocious puberty is associated with growth hormone therapy (1). The index patient was not on the growth hormone at the time of the diagnosis of precocious puberty. Gonadotropin-dependent precocious puberty is treated with gonadotropin analog to prevent short stature in adulthood and, behavioral issues with elevated sex hormone levels. In our patient, we did not use the gonadotrophin analogs to prevent the progression of puberty as his chronological age is close to 9 years and his behavior was not disturbed by the hormonal changes.

\section{References}

1. Monai E, Johansen A, Clasen-Linde E, Meyts ERD, Skakkebæk NE, Main KM, et al. Central Precocious Puberty in two Boys with Prader-Willi Syndrome on Growth Hormone Treatment. AACE Clin Case Reports. 2019;5(6):e352-6. 
2. Lee HS, Hwang JS. Central precocious puberty in a girl with Prader-Willi syndrome. J Pediatr Endocrinol Metab. 2013;26(11-12):1201-4.

3. MeaderB N, Albano A, Sekizkardes H, Delaney A. Heterozygous Deletions in MKRN3 Cause Central Precocious Puberty Without Prader-Willi Syndrome. The Journal of Clinical Endocrinology \&
Metabolism. 2020;105,(8) ::2732-39

4. Holm VA, Cassidy SB, Butler MG, et al. Prader-Willi syndrome: consensus diagnostic criteria. Pediatrics. 1993;91(2):398-402.

5. Kocjan A R, Lecka A, Malinowska A ,et al; Central precocious puberty in a boy with Prader-Willi syndrome; January 2005 Pediatria polska 80(10):929933 